\title{
PLANEJAMENTO, GESTÃo E SUSTENTABILIDADE DA ÁREA DE PROTEÇÃo AMBIENTAL DE JENIPABU, RIO GRANDE DO NORTE, BRASIL
}

\author{
Ilton Araújo Soares ${ }^{1}$ \\ William Gledson e Silva² \\ Jorge Eduardo Lins Oliveira ${ }^{3}$
}

Resumo: O objetivo deste artigo foi analisar a sustentabilidade da Área de Proteção Ambiental de Jenipabu - APAJ a partir das ações de planejamento, gestão e ordenamento territorial. Os procedimentos metodológicos deram-se com o uso de uma abordagem sistêmica, seleção e análise de indicadores de sustentabilidade para unidades de conservação - UC, e identificação das relações de causa e efeito entre os indicadores e suas interferências na sustentabilidade da UC. Os resultados apontaram que a maioria das relações entre os indicadores ocorreram de forma negativa, corroborando para que a APAJ apresentasse um quadro de insustentabilidade. Por fim, constatamos que a APAJ não tem um planejamento e gestão estratégicos que levem ao alcance dos seus objetivos de criação e a sua sustentabilidade.

Palavras-chave: Unidade de conservação. Indicadores de sustentabilidade. Áreas protegidas. Gestão costeira. Ciências ambientais

\section{PLANNING, MANAGEMENT AND SUSTAINABILITY OF THE ENVIRONMENTAL PROTECTION AREA OF JENIPABU, STATE OF RIO GRANDE DO NORTE, BRAZIL}

Abstract: The objective of this article was to analyze the sustainability of the Environmental Protection Area of Jenipabu - APAJ from the actions of planning, management and territorial planning. The methodological procedures were based on the use of a systemic approach, selection and analysis of sustainability indicators for protected areas - PA, and identification of cause and effect relationships between indicators and their interferences in the sustainability of PA. The results showed that the majority of the relationships between the indicators occurred in a negative form, confirming that APAJ presented a context of unsustainability. Finally, we found that APAJ does not have a strategic planning and management that leads to the achievement of its creation goals and its sustainability.

Keywords: Protected areas. Sustainability Indicators. Protected areas. Coastal Management. Environmental Sciences

\section{PLANIFICACIÓN, GESTIÓN Y SOSTENIBILIDAD DEL ÁREA DE PROTECCIÓN AMBIENTAL DE JENIPABU, ESTADO DEL RIO GRANDE DO NORTE, BRASIL}

Resumen: El objetivo de este artículo fue analizar la sostenibilidad del Área de Protección Ambiental de Jenipabu - APAJ a partir de las acciones de planificación,

\footnotetext{
${ }^{1}$ Universidade Federal do Rio Grande do Norte, Departamento de Oceanografia e Limnologia, Natal, Brasil, iltonet@yahoo.com.br, https://orcid.org/0000-0002-9130-9622

2 Universidade do Estado do Rio Grande do Norte, Departamento de Economia, Açu, Brasil, williangledson@gmail.com, https://orcid.org/0000-0003-0552-202X

${ }^{3}$ Universidade Federal do Rio Grande do Norte, Departamento de Oceanografia e Limnologia, Natal, Brasil, jorgelins@ufrnet.br, https://orcid.org/0000-0002-2841-7102
} 
gestión y ordenamiento territorial. Los procedimientos metodológicos se dieron con el uso de un enfoque sistémico, selección y análisis de indicadores de sostenibilidad para unidades de conservación - UC, y la identificación de las relaciones de causa y efecto entre los indicadores y sus interferencias en la sostenibilidad de la UC. Los resultados mostraron que la mayoría de las relaciones entre los indicadores ocurrieron de manera negativa, corroborando para que la APAJ presentase una situación de insostenibilidad. Finalmente, descubrimos que APAJ no tiene una planificación y gestión estratégica que conduzca al logro de sus objetivos de creación y su sostenibilidad.

Palabras clave: Unidad de conservación. Indicadores de sostenibilidad. Áreas protegidas. Gestión costera. Ciencias ambientales

\section{Introdução}

Unidades de conservação - UCs são territórios especialmente protegidos, com objetivo de garantir a proteção da biodiversidade, das paisagens, das populações tradicionais e o uso sustentável dos recursos naturais (BRASIL, 2005). Essas áreas são fundamentais para o alcance da sustentabilidade do planeta Terra através da prestação de uma série de serviços, tais como: manutenção de processos ecológicos e da capacidade produtiva dos ecossistemas; preservação das características socioeconômicas e culturais das populações tradicionais; fornecimento de bens e serviços ambientais; criação de oportunidades para o desenvolvimento econômico de comunidades locais; desenvolvimento de atividades recreativas, educação ambiental e turismo (CIFUENTES; IZURIETA; FARIAS, 2000; ARAÚJO, 2012; SALVIO, 2017).

Entretanto, o ato de criar UCs por si só não garante a proteção da biodiversidade nem o seu ordenamento territorial. De acordo com Silva et al. (2018), nas duas últimas décadas tem ocorrido uma relação inversamente proporcional entre o aumento de áreas protegidas e a perda de cobertura vegetal. Portanto, é preciso proporcionar as condições necessárias de gestão para que as UCs possam alcançar os objetivos para os quais foram criadas (ARAÚJO; CABRAL; MARQUES, 2012). E para isso é imprescindível garantir a sustentabilidade da UC em curto, médio e longo prazos.

A definição de sustentabilidade está diretamente associada à ideia de desenvolvimento sustentável. Dentre as possíveis definições podemos caracterizá-la como "[...] a manutenção quantitativa e qualitativa dos recursos ambientais [...]" (AFONSO, 2006, p. 11). Para Bellen (2006, p. 31) "[...] a idéia de sustentabilidade está ligada à persistência de certas características necessárias e desejáveis de 
pessoas, suas comunidades e organizações, e os ecossistemas que as envolvem, dentro de um período de tempo longo e indefinido".

No caso específico das UCs à sustentabilidade está associada à existência e permanência das condições necessárias para manutenção da sua qualidade ecológica e socioeconômica. Portanto, é um processo contínuo de busca da efetividade de gestão, proteção da biodiversidade e justiça social. Para que isso ocorra é necessário um processo de planejamento e gestão estratégica, sistêmico, holístico e participativo, associado à infraestrutura de recursos humanos e financeiros para dar suporte às demandas exigidas para alcançar a sustentabilidade. Adicionado a esses fatores, a sustentabilidade de uma UC também está relacionada à existência e eficácia dos instrumentos de planejamento e gestão, principalmente o plano de manejo, o zoneamento e o conselho gestor, de modo que garantam a proteção da biodiversidade, o ordenamento territorial e o alcance dos objetivos de criação da UC.

O uso de indicadores, por sua vez, é uma das principais formas de estudar a sustentabilidade. São ferramentas que possibilitam a partir de uma abordagem sistêmica analisar cenários de um dado espaço geográfico, de uma atividade humana ou empreendimento (PRESCOTT-ALLEN, 1997; BELLEN, 2004; BELLEN, 2006; TAYRA; RIBEIRO, 2006). Dessa maneira, a importância da utilização de indicadores está na contribuição que essas ferramentas podem trazer para a definição de estratégias em busca da sustentabilidade do uso dos recursos naturais e da relação natureza/sociedade.

No tocante à sustentabilidade das UCs brasileiras, de maneira geral, elas apresentam uma série de dificuldades, em função principalmente da falta de gestão e infraestrutura adequadas para enfrentar os desafios e garantir a proteção da biodiversidade (MORSELLO, 2006; DOUROJEANNI; PADUA, 2007; DOUROJEANNI; PADUA, 2013).

As UCs da categoria Área de Proteção Ambiental - APA, que pertencem ao grupo de UCs de uso sustentável, são as mais flexíveis do ponto de vista da ocupação territorial e utilização dos recursos naturais (DOUROJEANNI; PADUA, 2013). Diante disso, de acordo com suas características ecológicas e socioeconômicas e dos processos de planejamento e gestão, as APAs podem ter pouca capacidade de proteger a biodiversidade e de garantir o ordenamento territorial, fatores diretamente relacionados à sustentabilidade das UCs. 
No Rio Grande do Norte existem cinco APAs, que juntas representam 77,8\% do total dos territórios continental e marinho protegidos pelo sistema de unidades de conservação do estado, protegendo principalmente ambientes costeiros associados à Mata Atlântica, campos dunares e o bioma marinho. Dentre essas UCs está a Área de Proteção Ambiental de Jenipabu - APAJ, localizada na Região Metropolitana de Natal, com uma área de aproximadamente 1.800 ha, e que foi criada para proteger a biodiversidade e os ecossistemas costeiros, principalmente os campos de dunas fixas e móveis e o manguezal (RIO GRANDE DO NORTE, 1995; RIO GRANDE DO NORTE, 2009).

A APAJ é um dos principais pontos turísticos do Rio Grande no Norte devido suas paisagens naturais e os passeios de buggy nos campos de dunas. Entretanto, apesar de sua importância ecológica e socioeconômica, apresenta uma série de dificuldades para alcançar os seus objetivos de criação, o que provoca como consequência, diversos conflitos socioambientais, como ocupação irregular por construções dos campos de dunas e falta de fiscalização e monitoramento da atividade turística (SOARES; OLIVEIRA; LIMA, 2018). Diante deste contexto, a problemática deste trabalho perpassa pela investigação das relações entre 0 planejamento, a gestão e sustentabilidade da APAJ. Neste sentido, o objetivo deste artigo foi analisar a sustentabilidade da APAJ a partir das ações de planejamento, gestão e ordenamento territorial.

\section{Material e métodos}

Caracterização da área de estudo

A Área de Proteção Ambiental de Jenipabu é uma UC de uso sustentável, de acordo com o Sistema Nacional de Unidades de Conservação - SNUC (BRASIL, 2005). Foi criada em 1995 pelo Decreto Estadual n 12.620/1995 e localiza-se nos municípios de Extremoz (97\%) e Natal (3\%), na Região Metropolitana de Natal, estado do Rio Grande do Norte (Figura 1) (RIO GRANDE DO NORTE, 2006). É uma UC costeira formada por diversas unidades geoambientais ${ }^{4}$ como, dunas fixas e móveis, manguezal, planície flúvio-marinha e tabuleiro costeiro.

\footnotetext{
${ }^{4}$ Unidades geoambientais são áreas com características físicas e ambientais homogêneas.
} 
A APAJ tem uma população estimada de 4.000 habitantes $^{5}$ (IBGE, 2018) e densidade demográfica de aproximadamente $230 \mathrm{hab} . / \mathrm{km}^{2}$. A principal atividade econômica desenvolvida em seu território é o turismo, principalmente os passeios de buggy sobre os campos de dunas, tornando-a um dos principais atrativos turísticos do estado. Também são desenvolvidas atividades agropecuárias, principalmente nas áreas de tabuleiro e planície fluvial, com pequenas criações de animais e plantio de culturas permanentes e temporárias, como abacate (Persea americana), feijão (Phaseolus vulgaris), banana (Musa acuminata), hortaliças, coco da baía (Cocos nucifera) e milho (Zea mays).

Figura 1 - Mapa de localização da Área de Proteção Ambiental de Jenipabu

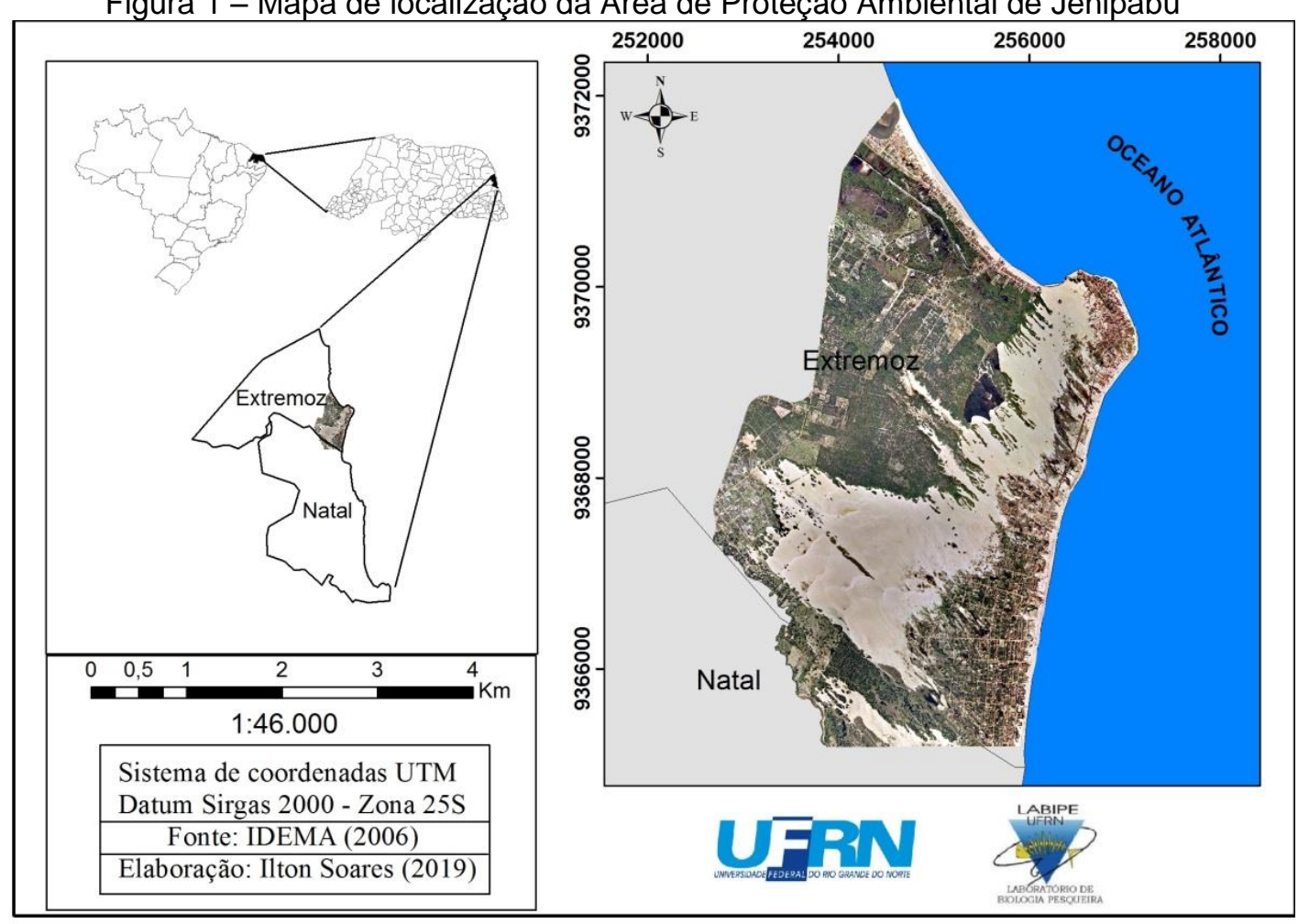

Procedimentos metodológicos

Os procedimentos metodológicos deste trabalho partiram da seleção e análise de um conjunto de indicadores de sustentabilidade de UC. Adotamos uma abordagem qualitativa onde o estudo integrado dos indicadores possibilitou discutir a sustentabilidade da APAJ.

\footnotetext{
${ }^{5}$ Foram considerados os dados dos setores censitários do IBGE.
} 
De acordo com Araújo, Cabral e Marques (2012), é preciso ter um entendimento e uma visão sistêmica da gestão das unidades de conservação. Portanto, utilizamos uma análise sistêmica dos indicadores, buscando identificar suas relações e de que forma afetam a sustentabilidade da UC, a partir de uma perspectiva holística e integrada dentro de uma visão de totalidade do meio investigado (CHRISTOFOLLETTI, 1999; SALES, 2004; BELLEN, 2006; RODRIGUEZ; SILVA; 2013).

A estratégia metodológica buscou identificar as relações de causa e efeito entre os indicadores e suas interferências (positiva ou negativa) na sustentabilidade da UC. De forma genérica, partimos do pressuposto de que todos os indicadores interagem entre si e afetam de maneira direta ou indireta a sustentabilidade da UC (Figura 2).

Figura 2 - Modelo de representação das interações possíveis entre os indicadores de sustentabilidade.

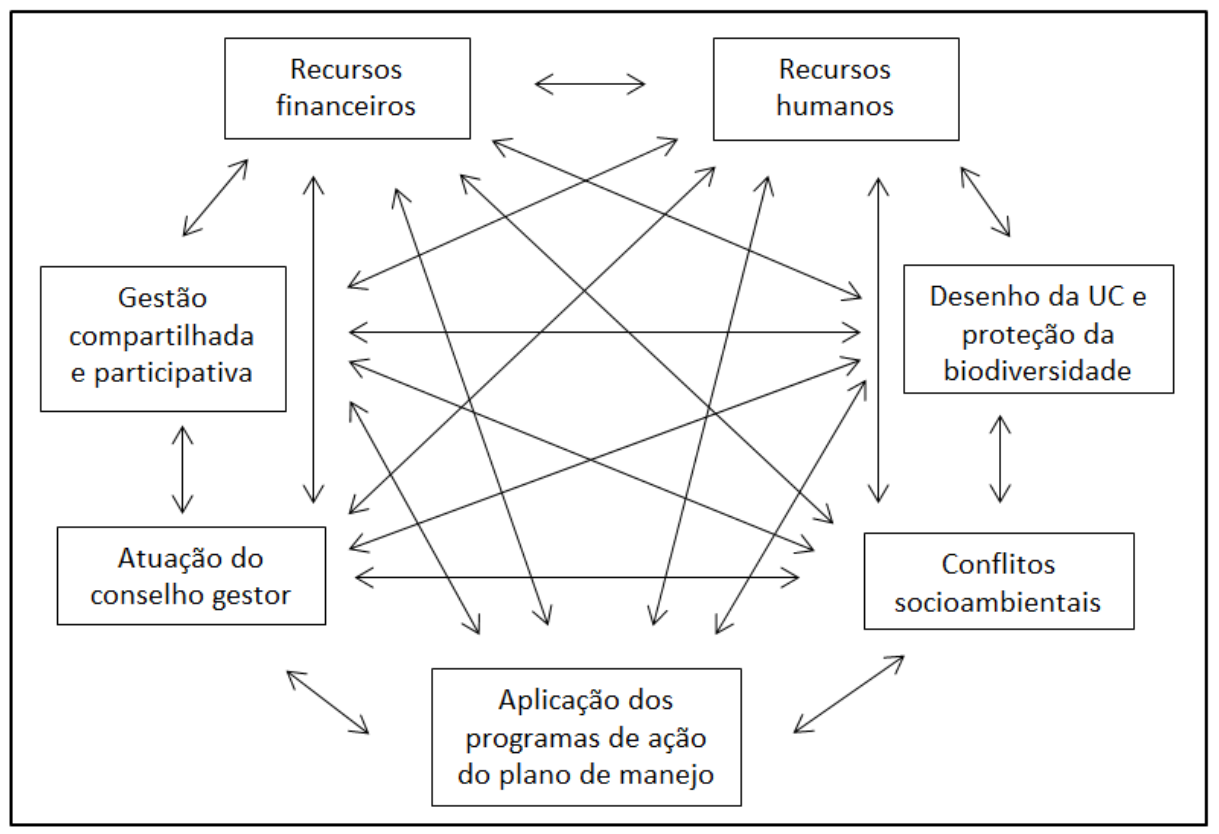

Fonte: Elaborado pelos autores (2018)

A pesquisa foi dividida nas seguintes etapas:

Revisão de literatura - Foi feita uma revisão com foco nos principais conceitos utilizados na pesquisa, quais sejam: unidade de conservação, sustentabilidade, planejamento, gestão e indicadores de sustentabilidade.

Seleção dos indicadores - Foram selecionados 07 indicadores para análise da sustentabilidade da APAJ que abrangem as dimensões ambiental, social, 
econômica, institucional e de planejamento e gestão, permitindo uma análise multidimensional da área estudada (Quadro 1).

Quadro 1 - Indicadores de sustentabilidade para a Área de Proteção Ambiental de Jenipabu

\begin{tabular}{|c|c|}
\hline Indicadores & Importância do indicador para a sustentabilidade da UC \\
\hline $\begin{array}{l}\text { Aplicação dos programas } \\
\text { de ação do plano de } \\
\text { manejo }\end{array}$ & $\begin{array}{l}\text { Os programas de ação do plano de manejo devem refletir a visão } \\
\text { sistêmica da gestão da UC, os seus objetivos de criação e os } \\
\text { principais problemas e desafios identificados na etapa de } \\
\text { diagnóstico. Desta forma, este indicador objetiva analisar esses } \\
\text { aspectos descritos acima, a operacionalização e eficácia dos } \\
\text { programas de ação estabelecidos no plano de manejo e de que } \\
\text { forma afetam a sustentabilidade da UC. }\end{array}$ \\
\hline Recursos financeiros & $\begin{array}{l}\text { Os recursos financeiros são fundamentais para gestão da unidade } \\
\text { de conservação. Com isso, esse indicador busca analisar as } \\
\text { fontes de recursos, a dotação orçamentária e se os recursos } \\
\text { financeiros destinados à UC são suficientes para a sua gestão. }\end{array}$ \\
\hline Recursos humanos & $\begin{array}{l}\text { A operacionalização e gestão da UC dependem diretamente da } \\
\text { existência de recursos humanos suficientes e capacitados, } \\
\text { geralmente divididos em equipe administrativa e equipe técnica, } \\
\text { sendo a segunda, responsável pelas ações de manejo, } \\
\text { fiscalização e monitoramento da UC. Portanto, esse indicador tem } \\
\text { a função de identificar se os recursos humanos existentes } \\
\text { correspondem a sua necessidade de gestão. }\end{array}$ \\
\hline $\begin{array}{c}\text { Gestão compartilhada e } \\
\text { participativa }\end{array}$ & $\begin{array}{l}\text { A gestão compartilhada e participativa é uma das principais } \\
\text { estratégias para alcançar a sustentabilidade de UCs, } \\
\text { principalmente aquelas que envolvem mais de um município, onde } \\
\text { suas terras não precisam ser desapropriadas e que são habitadas } \\
\text { por comunidades humanas, como por exemplo, as APAs. Essas } \\
\text { características fazem dessas UCs muitas vezes espaços de } \\
\text { conflitos, o que torna necessária uma gestão que envolva vários } \\
\text { entes federativos e da sociedade civil organizada, que têm um } \\
\text { papel decisivo no ordenamento territorial e na resolução de } \\
\text { conflitos socioambientais. }\end{array}$ \\
\hline $\begin{array}{c}\text { Atuação do conselho } \\
\text { gestor }\end{array}$ & $\begin{array}{l}\text { O conselho gestor é um dos principais instrumentos de gestão e } \\
\text { tomada de decisão da UC. Desta forma, partimos do pressuposto } \\
\text { de que quanto maior for a atuação e a influência do conselho } \\
\text { gestor na tomada de decisões, maiores as possibilidades da UC } \\
\text { ser sustentável. }\end{array}$ \\
\hline $\begin{array}{c}\text { Desenho da UC e } \\
\text { proteção da } \\
\text { biodiversidade }\end{array}$ & $\begin{array}{l}\text { O desenho da UC é de grande importância para atingir seus } \\
\text { objetivos de criação. Uma UC mal dimensionada territorialmente } \\
\text { pode afetar negativamente o seu ordenamento territorial e a } \\
\text { proteção dos recursos naturais. Este indicador tem o propósito de } \\
\text { apontar a relação entre o desenho da UC e a proteção dos seus } \\
\text { ecossistemas. }\end{array}$ \\
\hline $\begin{array}{l}\text { Existência e magnitude de } \\
\text { conflitos socioambientais }\end{array}$ & $\begin{array}{l}\text { Este indicador é importante para análise da sustentabilidade de } \\
\text { UC porque está diretamente associado à existência e efetividade } \\
\text { dos instrumentos de gestão e eficácia dos programas de ação do } \\
\text { plano de manejo. Outro aspecto importante deste indicador é sua } \\
\text { capacidade de abordar espacialmente os impactos adversos que } \\
\text { ocorrem na UC. }\end{array}$ \\
\hline
\end{tabular}

Fonte: Elaborado pelos autores (2018).

Do ponto de vista metodológico e operacional adotamos os seguintes critérios para seleção dos indicadores: ser de fácil compreensão; ter valor técnico e científico; capacidade de comunicar a informação; facilidade de acesso aos dados para análise 
do indicador; permitam a análise sistêmica e integrada com os demais indicadores elencados; sejam condizentes com a abordagem proposta e as características do objeto de estudo (BELLEN, 2006; INDICATORS..., 2007; SINGH et al., 2012; MARTINS; CÂNDIDO, 2012; FEIL; SCHREIBER, 2017; SALVIO, 2017).

Do ponto de vista do objetivo da pesquisa os critérios adotados para escolha foram: importância para a execução das ações de planejamento e gestão da UC; relevância para alcance dos objetivos de criação da UC estabelecidos no seu plano de manejo; capacidade de compreensão do contexto socioespacial da UC; e capacidade de refletir as ações em busca da sustentabilidade da UC.

Para a avaliação da contribuição de cada indicador para a sustentabilidade adotamos duas categorias de classificação a partir das relações entre os indicadores. Foi considerada uma relação positiva quando o indicador afetou positivamente outro(s) indicador(es) e a sustentabilidade da UC, e relação negativa quando $\mathrm{o}$ indicador afetou negativamente outro(s) indicador(es) e a sustentabilidade da UC.

Leitura e análise das atas e participação nas reuniões do conselho gestor da APAJ foi realizada a leitura e análise das atas de reuniões ordinárias e extraordinárias do conselho gestor com período da amostragem de 2006 (ano da criação do conselho gestor) até maio de 2017 , totalizando 70 documentos $^{6}$. Com as atas foi utilizada a análise de conteúdo (BARDIN, 2011), buscando identificar as discussões que abordassem temas correlatos aos indicadores utilizados na pesquisa. A participação nas reuniões deu-se nos anos de 2017 e 2018 e objetivou observar in loco as discussões, deliberações, os processos de tomada de decisão, gestão participativa e a representatividade das instituições que compõem o conselho gestor.

Pesquisas de campo - subsidiaram a caracterização da área de estudo, identificação de conflitos e análise do desenho da UC.

Entrevistas - Foram realizadas entrevistas semiestruturadas com o gestor da APAJ e a diretora técnica do Núcleo de Unidades de Conservação do Instituto de Desenvolvimento Sustentável e Meio Ambiente do Rio Grande do Norte - IDEMA, órgão responsável pela gestão das UCs do estado, com o objetivo de coletar informações para a análise dos indicadores utilizados na pesquisa.

Análise dos programas de ação do plano de manejo - nessa etapa da pesquisa foi analisada a coerência dos programas de ação do plano de manejo com os objetivos

${ }^{6}$ Todas as atas consultadas foram aprovadas pelo conselho gestor. 
de criação da UC; as relações entre os programas de ação e os principais conflitos e desafios da UC; e a aplicação e eficácia dos programas de ação.

\section{Resultados e discussão}

A seguir são apresentados os resultados da análise dos indicadores utilizados neste estudo.

Aplicação dos programas de ação do plano de manejo

Os programas de ação são partes integrantes do plano de manejo e agrupam temas específicos que versam sobre as ações para a gestão e alcance dos objetivos da UC (ARAÚJO; CABRAL; MARQUES; 2012). Esses programas devem apresentar em sua estrutura os objetivos, metas, ações, indicadores de avaliação de resultados e de desempenho, metodologias, recursos humanos e, quando necessário, fontes dos recursos financeiros, e devem estar alinhados de forma sistêmica e estratégica para facilitar o alcance dos seus objetivos (IBAMA, 2001; BRASIL, 2011; LIÇÕES..., 2013).

O plano de manejo da APAJ contem cinco programas de ação: programa de operacionalização, marketing e divulgação, monitoramento, fiscalização e educação ambiental. Esses programas apresentam algumas fragilidades, quais sejam: indicadores insuficientes ou inadequados; falta de metas para os objetivos e atividades propostas; falta de integração e de abordagem sistêmica entre parte dos programas; as metodologias dos programas são quase todas descritas de forma superficial, sendo que a maioria é apenas citada, sem nenhuma explicação sobre as técnicas e procedimentos para execução das ações.

O programa de operacionalização trata da estrutura física e humana para o desenvolvimento das ações da APAJ. Em relação aos recursos humanos, indica apenas a necessidade de um gestor e equipe de apoio administrativo. Não aborda a precisão de uma equipe de analistas ambientais para desenvolvimento das atividades de fiscalização, monitoramento, pesquisa e auxílio ao gestor da UC. Já o programa de marketing discorre sobre uma série de ações para divulgação e auxílio à gestão da APAJ.

Em relação à implementação dos programas de fiscalização e educação ambiental, algumas ações foram realizadas de forma pontual, isoladas e outras 
nunca foram aplicados. No que se refere à educação ambiental, por exemplo, foram desenvolvidas algumas atividades em parceria com as escolas localizadas na UC, geralmente na semana do meio ambiente. Já as ações do programa de monitoramento nunca foram implementadas, como por exemplos, os monitoramentos do tráfego de buggys e das construções irregulares sobre os campos de dunas. Isso ocorre porque não há recursos humanos, financeiros e um planejamento estratégico anual a partir dos programas de ação estabelecidos no plano de manejo. Outro motivo é a inexistência de gestão compartilhada entre o órgão gestor da APAJ e as prefeituras de Natal e de Extremoz para implantação e operacionalização dos programas de ação, principalmente os de fiscalização.

Em razão disso, os programas de ação do plano de manejo da APAJ não foram implementados. O que ocorre de fato é algo semelhante ao cenário de grande parte das UCs do Brasil. De acordo com Dourojeanni (2003), a não aplicação do plano de manejo é uma realidade da maior parte das UCs brasileiras. Um estudo feito pelo autor supracitado com a revisão de mais de 50 planos de manejo, aponta que apenas $10 \%$ foram considerados úteis para a gestão das UCs. Cabral (2012) apresenta dados semelhantes ao afirmar que a eficácia da implementação das estratégias para gestão de UCs fica entre 10\% e 20\%.

Outro problema muito comum nos planos de manejo é que sua parte analítica e propositiva (os programas de ação) é sucinta e de baixa utilidade prática (DOUROJEANNI, 2003). De modo similar, isso também ocorre com o plano de manejo da APAJ, haja vista que os programas de ação configuram-se como uma lista de ações a serem desenvolvidas, sem indicações mais precisas sobre as metas, atividades e indicadores, tendo pouca ou nenhuma capacidade de implantação e operacionalização.

O plano de manejo deve estabelecer prioridades concretas (DOUROJEANNI, 2003). Com isso, é importante que os programas relacionados com os principais conflitos e impactos adversos sejam considerados como prioritários e tenham um maior grau de detalhamento quanto ao objetivo, indicadores, metodologia, metas, resultados esperados, recursos humanos e financeiros. Já os demais programas podem ser elaborados com maiores detalhes nos planos operacionais anuais POAs, que devem estar dentro do planejamento estratégico da UC. No caso dos programas do plano de manejo da APAJ, apenas o de fiscalização cita algumas diretrizes para ações prioritárias. Num contexto de escassez de recursos financeiros 
e humanos, o estabelecimento de ações e programas de gestão prioritários é ainda mais imprescindível.

Face ao exposto, tornam-se necessárias a revisão e restruturação dos programas de ação do plano de manejo com destaque para: inserção de mais indicadores de desempenho e de resultado para avaliar o alcance das metas e objetivos dos programas de ação, descrição das metodologias de implementação dos programas e verificação dos indicadores e, estabelecer atividades e metas para os programas. Outras medidas importantes são: a criação de um programa de uso público, uma vez que a APAJ é um dos atrativos turísticos do Rio Grande do Norte que mais recebe visitantes, e a criação de um subprograma de monitoramento da dinâmica dos campos de dunas, devido o grande tráfego de buggys na UC.

O quadro 2 apresenta uma avaliação sinóptica dos programas de ação.

Quadro 2 - Sinopse da análise dos programas de ação do plano de manejo da APAJ

\begin{tabular}{|l|c|c|c|c|c|}
\hline & $\begin{array}{c}\text { Programa de } \\
\text { operacionalização }\end{array}$ & $\begin{array}{c}\text { Programa } \\
\text { de } \\
\text { marketing }\end{array}$ & $\begin{array}{c}\text { Programa de } \\
\text { monitoramento }\end{array}$ & $\begin{array}{c}\text { Programa } \\
\text { de } \\
\text { fiscalização }\end{array}$ & $\begin{array}{c}\text { Programa } \\
\text { de } \\
\text { Educação } \\
\text { Ambiental }\end{array}$ \\
\hline $\begin{array}{l}\text { Há Integração } \\
\text { com os } \\
\text { demais } \\
\text { programas? }\end{array}$ & Sim & Parcialmente & Parcialmente & Parcialmente & Parcialmente \\
\hline $\begin{array}{l}\text { Os } \\
\text { indicadores } \\
\text { são } \\
\text { adequados? }\end{array}$ & Não se aplica & Não & Parcialmente & Não & Não \\
\hline $\begin{array}{l}\text { A } \\
\text { Metodologia } \\
\text { é clara e } \\
\text { objetiva? }\end{array}$ & Não se aplica & Parcialmente & Não & Parcialmente & Não \\
\hline $\begin{array}{l}\text { Os objetivos } \\
\text { são claros? }\end{array}$ & Sim & Sim & Sim & Sim & Sim \\
\hline $\begin{array}{l}\text { Existem } \\
\text { metas claras } \\
\text { e objetivas? }\end{array}$ & Não se aplica & Não & Não & Não & Não \\
\hline $\begin{array}{l}\text { Há } \\
\text { Integração } \\
\text { com o } \\
\text { diagnóstico e } \\
\text { principais } \\
\text { desafios da } \\
\text { UC? }\end{array}$ & Não se aplica & Parcialmente & Sim & Sim & Parcialmente \\
\hline
\end{tabular}

Fonte: Elaborado pelos autores (2018)

Recursos financeiros

Historicamente, os recursos financeiros destinados às UCs brasileiras têm sido insuficientes para assegurar a gestão dessas áreas e a proteção da 
biodiversidade. Os valores têm oscilado ao longo dos anos de acordo com as conjunturas econômicas e as políticas de governo adotadas, entretanto, estão sempre aquém das demandas para garantir o mínimo funcionamento das UCs (DOUROJEANNI; PÁDUA, 2007). Na década passada a relação entre o aumento da quantidade de UCs e seu orçamento foi inversamente proporcional (DOUROJEANNI; PÁDUA, 2013). Estudo feito por Silva et al. (2018) sobre as UCs estaduais de Pernambuco aponta situação semelhante ao contexto brasileiro.

A realidade das UCs estaduais do Rio Grande do Norte não difere do cenário nacional. Não são destinados recursos financeiros suficientes para o planejamento e gestão das UCs potiguares, o que torna a operacionalização e gestão dessas áreas um grande desafio. Os recursos financeiros investidos são oriundos da arrecadação própria do órgão gestor da UC e através de compensações ambientais e medidas compensatórias, destinados geralmente de forma pontual, sem a existência de planejamento estratégico para o sistema estadual de unidades de conservação e planos de trabalho com previsão de investimentos.

Todo esse quadro também ocorre na APAJ, que não dispõe de orçamento específico para sua gestão e não tem sustentabilidade econômica, uma vez que a receita advinda com a cobrança da entrada na sede da UC é muito inferior a sua demanda financeira. Além disso, esse recurso é destinado para conta única do governo do estado, o que dificulta e burocratiza o acesso a essas receitas pelo gestor da UC. Como consequência, a escassez de recursos financeiros inviabiliza quase todas as ações necessárias para a gestão da APAJ, como contratação de equipe técnica, desenvolvimento de pesquisas e implementação do plano de manejo.

A APAJ tem um grande potencial financeiro em função da quantidade de passeios de buggy nos campos de dunas. De acordo com o presidente do Sindicato dos Bugueiros do Rio Grande do Norte, na alta estação, que vai do final de dezembro até fevereiro, são realizados mais de 400 passeios para a UC diariamente. Portanto, uma possibilidade de fonte de recursos financeiros é através da cobrança pelo acesso dos buggys aos mirantes da lagoa de Jenipabu, área de APAJ que foi desapropriada e pertence ao governo do estado. $O$ valor arrecadado poderia custear ao menos parte das ações de monitoramento e fiscalização na UC.

Outras ações que podem ser desenvolvidas para angariar recursos financeiros são: parcerias entre instituições públicas e privadas que têm relação com 
a APAJ, concorrer a editais de financiamento de projetos para UCs e criação do ICMS ecológico.

\section{Recursos humanos}

O déficit e a qualificação de recursos humanos são alguns dos principais problemas das UCs brasileiras. O Brasil tem uma média de funcionários por $\mathrm{km}^{2}$ de área protegida bem inferior aos países que mais investem em proteção da biodiversidade (DOUROJEANNI; PÁDUA, 2013). O Instituto Chico Mendes de Conservação da Biodiversidade - ICMBio, responsável pela gestão das UCs federais tem apenas 1.009 analistas ambientais para 335 UCs, o que dá uma média de três analistas por área protegida e de um analista ambiental para cada $1.701 \mathrm{~km}^{2}$ de área protegida, considerando as UCs continentais e marinhas (ICMBIO, 2018). O órgão gestor das UCs estaduais do Rio Grande do Norte, da mesma forma, tem um enorme déficit de recursos humanos para desenvolver as atividades sob sua responsabilidade.

A APAJ tem 13 funcionários, sendo: sendo um gestor e os demais divididos entre funções administrativas, manutenção, segurança e controle de acesso via portaria da UC. Não há analista ambiental, função essencial para auxiliar o gestor na elaboração de projetos, fiscalização e monitoramento. A ausência de uma equipe técnica de analistas ambientais é o principal problema no tocante aos recursos humanos da APAJ, o que reflete diretamente na aplicação dos programas de ação do plano de manejo e ampliação dos conflitos socioambientais.

Gestão compartilhada e participativa

A gestão compartilhada e participativa é apontada de forma sucinta e genérica nos programas de ação da APAJ. De acordo com o seu gestor, não há ações conjuntas entre a UC e a prefeitura de Natal. De fato, o que ocorrem são ações pontuais e isoladas de parceria para fiscalização entre o IDEMA e a prefeitura de Extremoz, geralmente com o apoio da Companhia de Policiamento Ambiental da Polícia Militar. Essas ações se dão principalmente para fiscalização das construções irregulares no campo de dunas da $\mathrm{ATE} 1^{7}$, uma das áreas mais conflituosas da APAJ. Além disso, na leitura das atas do conselho gestor fica evidente a negligência

\footnotetext{
7 Área de tratamento especial - é uma porção da APAJ delimitada pelo seu zoneamento com construções irregulares. Existem quatro ATEs na área de estudo.
} 
da Prefeitura de Extremoz na fiscalização das normas de uso e ocupação estabelecidas no plano diretor municipal para a área da APAJ, principalmente os campos dunares, consideradas como áreas non aedificandi. Isto posto, constatamos que a APAJ não tem um processo de gestão compartilhada entre o governo do estado e os municípios de Natal e Extremoz.

No que tange as parcerias com ONGs, instituições privadas e de ensino também são pontuais. Alguns exemplos dessas parcerias são: ações de educação ambiental com ONGs e escolas públicas localizadas no interior da APAJ e projetos de pesquisa desenvolvidos por alguns pesquisadores da UFRN. Não existem programas, ações ou projetos de maior magnitude e impacto na gestão da UC.

Limont e Fisher (2012) apontam que a gestão participativa é o caminho para o exercício da cidadania, a troca de experiências e vivências, a melhoria da qualidade de vida das comunidades e a construção de estratégias de conservação das áreas protegidas. Entretanto, na APAJ a participação da comunidade na sua gestão é muito pequena. Dentre as razões para isso estão a comunicação insuficiente entre as ações desenvolvidas pela APAJ e as comunidades locais e falta de sentimento de pertencimento de grande parte da população que reside na UC, como apontou (SOARES; OLIVEIRA; LIMA, 2018).

\section{Atuação do conselho gestor}

O conselho gestor da APAJ foi criado em 2006, onze anos após a criação da UC. É composto por representantes do governo do estado, instituições federais, do executivo e legislativo dos municípios de Natal e Extremoz, representantes de instituições de ensino, ONGs ambientalistas, conselhos comunitários, setor de hotéis e restaurantes e sindicato estadual dos bugueiros. (RIO GRANDE DO NORTE, 2009).

A análise das atas das reuniões do conselho gestor mostrou que a entidade é atuante e busca contribuir com a gestão e tomada de decisões da APAJ. Nos seus primeiros anos de funcionamento havia uma maior participação das entidades que 0 compõem, o que refletiu num conjunto de cobranças, solicitações e debates conjuntos para tentar implementar ações de gestão e em busca de solucionar os principais conflitos da UC. Entretanto, nos últimos dois anos (2017 e 2018) algumas instituições deixaram de participar ou faltaram a maioria das reuniões ordinárias do conselho, como o IBAMA, ONGs ambientalistas, Universidade Federal do Rio 
Grande do Norte, Instituto Federal do Rio Grande do Norte, representantes do legislativo e executivo das prefeituras de Natal e Extremoz. Além disso, algumas entidades perderam o direito a vaga porque seus conselheiros ultrapassaram o limite de faltas, conforme estabelecido no regimento interno do conselho gestor (RIO GRANDE DO NORTE, 2007). As principais consequências disso foram o enfraquecimento do conselho enquanto entidade participativa e a diminuição de sua capacidade de contribuição com a gestão da UC.

A partir da análise das atas e da participação nas reuniões do conselho gestor nos anos de 2017 e 2018, ficou evidente que a principal causa para saída ou baixa assiduidade destas instituições foi a falta de implementação por parte do órgão gestor da APAJ das decisões tomadas nas reuniões do conselho. Apesar de ser um conselho deliberativo, grande parte das decisões tomadas não foi implementa pelo órgão gestor. Há um hiato entre as discussões e deliberações do conselho e as ações tomadas pelo órgão gestor da UC.

Todavia, apesar dos problemas expostos, o conselho gestor da APAJ tem dado relevantes contribuições para sua gestão, principalmente no exercício da gestão participativa, na cobrança de ações de fiscalização e controle das atividades ligadas ao turismo.

No entanto, as fragilidades da gestão da APAJ por parte do órgão gestor teve uma implicação direta na sua gestão participativa, uma vez que contribuiu para a redução da participação das instituições no conselho. Diante disso, é preciso criar estratégias para retomar a maior atuação das instituições envolvidas no conselho gestor, entretanto, para isso, o IDEMA precisa implementar um processo de gestão sistemática, compartilhada e contínua, com os recursos humanos, financeiros e operacionais necessários. Só assim, as instituições poderão voltar a acreditar na importância do conselho gestor da APAJ como uma entidade com potencial para contribuir com a gestão da UC.

Desenho da UC e proteção da biodiversidade

A maioria das teorias e metodologias para seleção de áreas a serem protegidas tem como referência a conservação da biodiversidade. Os critérios utilizados para identificação de áreas potenciais para conservação tem se baseado, sobretudo, na distribuição de espécies, habitats e ecossistemas. Além desses, outros critérios têm sido utilizados, quais sejam: valor recreativo, educacional e 
científico, grau de ameaça por impactos adversos, raridade e importância dos recursos culturais (ARAÚJO, 2012).

Em síntese, os aspectos utilizados para criação de UCs envolvem as dimensões ecológica, econômica e político-institucional, entretanto, em grande medida não são observados pelos pesquisadores e tomadores de decisão responsáveis pela criação de áreas protegidas (MORSELLO, 2006). Assim sendo, a determinação errada dos limites da UC pode trazer sérios problemas para a sua gestão (DOUROJEANNI, 2003). Isso ocorre principalmente quando o perímetro delimitado não abarca as porções territoriais que mais precisam ser protegidas.

No caso da APAJ, sua criação deu-se em função da necessidade de proteção dos ecossistemas costeiros devido a sua importância ecológica e para o equilíbrio dinâmico do ambiente, e principalmente por causa das pressões e ameaças provocadas pelo processo de uso e ocupação do solo naquela região. Seu território envolve toda a área dos campos de dunas fixas e móveis utilizadas pela atividade turística para passeios de buggy e que sofre pressão da urbanização e especulação imobiliária, que estão entre os principais conflitos socioambientais da UC (SOARES; OLIVEIRA; LIMA, 2018). Portanto, seu desenho está alinhado aos seus objetivos de criação.

A APAJ tem seus limites claramente definidos através da rodovia estadual RN 304, do rio Doce e da linha de costa, o que facilita identificar seu perímetro (Figura 1). Teoricamente, isso é um aspecto positivo, uma vez que permite identificar visualmente e espacialmente os limites para aplicação das restrições de uso impostas pelo zoneamento da UC, o que por sua vez cria condições para o melhor manejo dos recursos naturais e proteção da biodiversidade. $O$ fato de a APAJ ter uma pequena extensão territorial, (menos de 2 mil hectares) quando comparada com a maior parte das APAs do Brasil, também é um fator que, teoricamente, favorece o ordenamento territorial e a gestão dos recursos naturais, uma vez que demanda menor infraestrutura.

O desenho e as características geoambientais da APAJ também facilitam a identificação e a delimitação espacial dos seus ecossistemas, o que é um fator positivo para a proteção e o manejo dos recursos naturais. Em campo podemos identificar facilmente as áreas de transição e os limites entre as unidades geoambientais. De acordo com Araújo (2012), algumas UCs não apresentam critérios específicos para a definição dos seus limites e não têm referências 
geográficas claras, o que dificulta a identificação do seu perímetro em campo e aplicação das limitações impostas pelo seu zoneamento, fatores que contribuem para geração de conflitos.

Entretanto, ter limites adequados aos seus objetivos de criação e claramente definidos por si só não garante a gestão adequada e a proteção da biodiversidade. Isto só ocorre de fato, quando associado à implementação e eficácia dos programas de ação do plano de manejo, de forma que garantam a proteção e o uso sustentável dos recursos naturais e o ordenamento territorial.

No que se refere ao tamanho, a APAJ atende parcialmente aos seus objetivos de criação. Seus principais ecossistemas protegidos são as dunas e o manguezal, sendo que este se estende por uma área fora dos limites da UC, no estuário do rio Ceará-Mirim. Do ponto do vista do seu desenho, tamanho e pensando em garantir um maior ordenamento territorial e planejamento integrado, a APAJ poderia ser ampliada e englobar a área do estuário do rio Ceará-Mirim que abarca o ecossistema de manguezal, que de acordo com Guedes (2018), tem uma área de 407 ha. Aproximadamente 20\% deste total já faz parte da APAJ. Apesar de já ser protegido por ser área de preservação permanente - APP, a inserção de toda a área de manguezal do estuário do Rio Ceará-Mirim na APAJ poderá possibilitar maior proteção a esse ecossistema se os programas de ação do plano de manejo forem efetivamente aplicados.

Existência e magnitude de conflitos socioambientais

Para Soares, Oliveira e Lima (2018, p. 492), no contexto das UCs, os conflitos geralmente ocorrem "[...] quando há uma disputa entre os interesses de conservação e de exploração dos recursos naturais [...]".

A APAJ foi criada num cenário socioespacial de conflitos socioambientais. A análise do seu processo histórico aponta dois motivos principais para sua criação: os passeios de buggy desenvolvidos de forma intensa e irregular e a ocupação inapropriada sobre os campos de dunas. Logo, as principais razões para criação da APAJ foram ordenar o uso e ocupação do solo, principalmente nos campos de dunas e garantir a proteção da biodiversidade.

Entretanto, estudo feito por Soares, Oliveira e Lima (2018) constatou que a criação da APAJ não conseguiu ordenar o uso e ocupação do solo nem dirimir os conflitos socioambientais que já existiam antes de sua criação. Os principais 
conflitos identificados foram: ocupação irregular das dunas fixas e móveis; uso irregular e intenso de trilhas por bugueiros; ocupação irregular da área de preservação permanente e planície fluvial do Rio Doce; disposição irregular de resíduos sólidos domiciliares e de construção civil (ocorre em todas as unidades geoambientais da APAJ); ocupação urbana desordenada da planície de deflação; disputa entre bugueiros e entre bugueiros e o órgão gestor da APAJ; e proibição de atividades culturais realizadas pela comunidade local (uso recreativo da lagoa de Jenipabu e coleta de frutas no campo de dunas) (SOARES; OLIVEIRA; LIMA, 2018).

Contraditoriamente, alguns desses conflitos aumentaram após a criação da APAJ, como por exemplo, a ocupação irregular das dunas fixas e móveis (SOARES; OLIVEIRA; LIMA, 2018), o que ratifica a constatação de que a criação da UC não conseguiu garantir o ordenamento territorial e uso sustentável dos recursos naturais. Portanto, a existência e magnitude de conflitos socioambientais afetaram diretamente a sustentabilidade da APAJ. Dentre as principais razões para ampliação dos conflitos estão a especulação imobiliária, a desobediência das normas de uso e ocupação determinadas pelo zoneamento da APAJ e a falta de fiscalização e monitoramento das atividades econômicas e formas de uso e ocupação do seu território.

Análise integrada dos indicadores e a sustentabilidade da APAJ

A análise integrada apontou que a maioria dos indicadores apresentou relações negativas para a sustentabilidade da APAJ. Apenas os indicadores "desenho da UC e proteção da biodiversidade" e "atuação do conselho gestor" obtiveram relação positiva com a sustentabilidade da UC (Quadro 3).

Quadro 3 - Sinopse dos resultados dos indicadores e relações com a sustentabilidade

\begin{tabular}{|c|c|c|}
\hline Indicadores & $\begin{array}{c}\text { Síntese dos resultados dos } \\
\text { indicadores }\end{array}$ & $\begin{array}{c}\text { Relação do indicador } \\
\text { com a sustentabilidade } \\
\text { da UC }\end{array}$ \\
\hline $\begin{array}{c}\text { Aplicação dos } \\
\text { programas de ação } \\
\text { do plano de manejo }\end{array}$ & $\begin{array}{c}\text { Foram realizadas apenas ações pontuais } \\
\text { e isoladas sem planejamento estratégico. }\end{array}$ & Negativa \\
\hline Recursos financeiros & $\begin{array}{c}\text { A UC não possui recursos financeiros } \\
\text { suficientes para garantir a sua gestão e } \\
\text { sustentabilidade. }\end{array}$ & Negativa \\
\hline Recursos humanos & $\begin{array}{c}\text { A UC não possui recursos humanos } \\
\text { suficientes para garantir a sua gestão e } \\
\text { sustentabilidade. }\end{array}$ & Negativa \\
\hline $\begin{array}{c}\text { Gestão } \\
\text { compartilhada e } \\
\text { participativa }\end{array}$ & Não há gestão compartilhada. & Negativa \\
\hline
\end{tabular}




\begin{tabular}{|c|c|c|}
\hline $\begin{array}{c}\text { Atuação do conselho } \\
\text { gestor }\end{array}$ & $\begin{array}{c}\text { A atuação do conselho gestor contribuiu } \\
\text { para atenuar parte dos conflitos } \\
\text { socioambientais da APAJ. }\end{array}$ & Positiva \\
\hline $\begin{array}{c}\text { Desenho da UC e } \\
\text { proteção da } \\
\text { biodiversidade }\end{array}$ & $\begin{array}{c}\text { O desenho da UC é coerente com seus } \\
\text { objetivos de criação e contribui para a } \\
\text { proteção dos ecossistemas costeiros. }\end{array}$ & Positiva \\
\hline $\begin{array}{c}\text { Existência e } \\
\text { magnitude de } \\
\text { Conflitos } \\
\text { socioambientais }\end{array}$ & $\begin{array}{c}\text { A UC apresenta um conjunto de conflitos } \\
\text { socioambientais que afetam o alcance } \\
\text { dos seus objetivos de criação e a sua } \\
\text { sustentabilidade. }\end{array}$ & Negativa \\
\hline
\end{tabular}

Fonte: Elaborado pelos autores (2018)

No que se refere às interações entre os indicadores, a maioria também foi negativa e indica que o desempenho do indicador "A" prejudica o indicador "B" (Figura 3). Como exemplo, a falta de recursos humanos e financeiros inviabilizou a implementação dos programas de ação do plano de manejo, que por sua vez, contribuiu para ampliação dos conflitos. Os indicadores "recursos financeiros" e "recursos humanos" tiveram a maior quantidade de outputs negativos, o que nos levou a inferir que foram aqueles que mais contribuíram para a insustentabilidade e dificuldades de gestão da APAJ.

Figura 3 - Relações entre os indicadores de sustentabilidade.

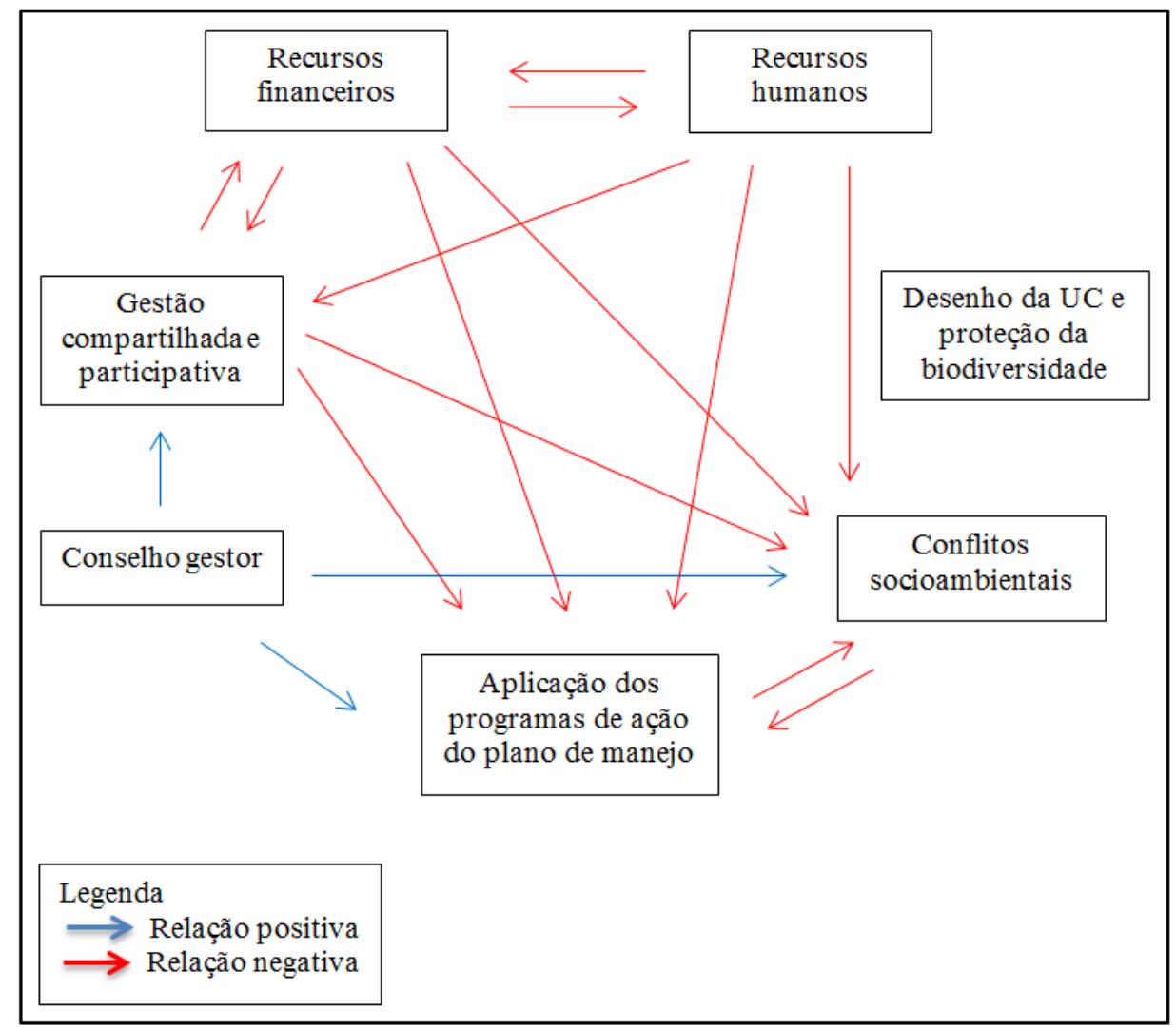

Fonte: elaborado pelos autores (2018). 
"Aplicação dos programas de ação do plano de manejo" e "existência e magnitude de conflitos socioambientais" foram os indicadores que mais receberam inputs negativos. Isto significa que foram os mais afetados negativamente nas relações com os demais indicadores. Entretanto, alguns indicadores apresentaram relações positivas, com por exemplo, a atuação do conselho gestor, que contribuiu para atenuar parte dos conflitos na APAJ e para implementação de algumas ações de fiscalização de forma conjunta entre as instituições responsáveis pela gestão da UC.

\section{Considerações finais}

A análise integrada dos indicadores evidenciou um quadro de insustentabilidade da APAJ e que há uma relação direta e negativa entre a falta de planejamento e gestão e a sua insustentabilidade. As principais causas desse quadro foram a insuficiência de recursos financeiros e humanos, a não aplicação dos programas de ação do plano de manejo e ausência de gestão estratégica e compartilhada.

Entretanto, diante do quadro desfavorável de planejamento e gestão da APAJ apresentado neste estudo, é preciso destacar três pontos importantes: a análise das atas evidenciou a tentativa e esforço dos gestores que estiveram a frente da UC para garantir a sua gestão sustentável, todavia, quase sempre esbarraram na falta de ações eficazes por parte do órgão gestor; a atuação do conselho gestor foi de fundamental importância para diminuir, ou na pior das hipóteses, evitar a ampliação da magnitude dos conflitos socioambientais da APAJ; também é preciso frisar que as ações pontuais $\mathrm{e}$ isoladas de fiscalização foram importantes para evitar a ocupação ainda maior dos campos de dunas. Apesar disso, essas mesmas ações ficaram muito aquém dos resultados que poderiam ser obtidos com a implantação de forma integrada de todos os programas de ação do plano de manejo da APAJ.

Apesar de os indicadores "atuação do conselho gestor" e "desenho da UC e proteção da biodiversidade" terem alcançado resultados satisfatórios, no contexto geral a APAJ apresenta sérios problemas para lograr êxito para atingir seus objetivos de criação. Os programas de ação do plano de manejo apresentam um conjunto de erros na sua elaboração, o que dificulta a sua aplicação. 
Portanto, o alcance da sustentabilidade da APAJ perpassa por um processo de mudança estrutural que envolve a necessidade de planejamento e gestão estratégicos do sistema estadual de UCs, ampliação de recursos humanos, financeiros, revisão e aplicação do plano de manejo e criação de uma cultura da gestão compartilhada e participativa entre governo do estado, prefeituras, setor empresarial e sociedade civil organizada.

Por fim, esta pesquisa apontou algumas ações que poderiam aumentar a capacidade de gestão da APAJ, assim como também seu potencial de proteção de ecossistemas costeiros, como por exemplos: a cobrança pelo acesso dos buggys aos mirantes da lagoa de Jenipabu, o que daria sustentabilidade financeira a UC; e o aumento da área da APAJ, protegendo todo ecossistema de manguezal do estuário do rio Ceará-Mirim. Entretanto, essas medidas não estão previstas nas ações de planejamento e gestão da UC. Diante deste contexto, a projeção futura para a APAJ é de um cenário pessimista com a manutenção do seu quadro de insustentabilidade e limitação do potencial de proteção dos ecossistemas costeiros associados ao bioma da Mata Atlântica.

\section{Referências}

AFONSO, Cintia Maria. Sustentabilidade: caminho ou utopia. São Paulo: Annablume, 2006.

ARAÚJO, Marcos A. R. Unidades de conservação: importância e história no mundo. In: Unidades de Conservação no Brasil: o caminho da gestão para resultados. São Carlos: RiMa, 2012.

ARAÚJO, Marcos A. R.; CABRAL, Rogério F. B.; MARQUES, Cleani P. Uma breve história sobre a gestão de unidades de conservação no Brasil. In: Unidades de Conservação no Brasil: o caminho da gestão para resultados. São Carlos: RiMa, 2012.

BARDIN, L. Análise de conteúdo. São Paulo: Edições 70, 2011.

BELLEN, Hans Michael Van. Desenvolvimento Sustentável: uma descrição das principais ferramentas de avaliação. Ambiente \& Sociedade, v. 7, n. 1, p. 67-88, jan./jun., 2004. Disponível em: http://www.scielo.br/pdf/asoc/v7n1/23537.pdf. Acesso em: 12 jul. 2016. BELLEN, Hans Michael Van. Indicadores de sustentabilidade: uma análise comparativa. 2. ed. Rio de Janeiro: FGV Editora, 2006.

BRASIL. Constituição Federal: coletânea de legislação de direito ambiental. Organizado por Odete Medauar. 4. ed. São Paulo: Ed. Revistas dos Tribunais, 2005.

BRASIL. Ministério do Meio Ambiente. Roteiro Metodológico de Planejamento Parque Nacional, Reserva Biológica e Estação Ecológica. [Brasília: MMA], 2011.

CABRAL, Rogério $F$. B. As pontes entre a estratégia e a execução das unidades de conservação. In: Unidades de Conservação no Brasil: o caminho da gestão para resultados. São Carlos: RiMa, 2012.

CHRISTOFOLLETTI, Antônio. Modelagem de sistemas ambientais. São Paulo: Edgar Blucher, 1999.

CIFUENTES, Miguel; IZURIETA, Arturo; FARIA, Helder Henrique de. Medición de la efectividad del manejo de areas protegidas. Turrialba: WWF:IUCN: GTZ, 2000.

DOUROJEANNI, Marc J. Análise Crítica dos Planos de Manejo de Áreas Protegidas no 
Brasil. In: BAGER, Alex (ed.). Áreas Protegidas: Conservação no Âmbito do Cone Sul. Pelotas, 2003. p. 1-20. Disponível em:

https://www.academia.edu/5669109/Analise critica de planos de manejo?auto=download.

Acesso em: 16 nov. 2018.

DOUROJEANNI, Marc J.; PÁDUA, Maria Tereza Jorge. Arcas à deriva: unidades de conservação do Brasil. Rio de Janeiro: Technical Books, 2013.

DOUROJEANNI, Marc J.; PÁDUA, Maria Tereza Jorge. Biodiversidade: a hora decisiva. 2. ed. Curitiba: Ed. UFPR, 2007.

FEIL, Alexandre André; SCHREIBER, Dusan. Análise da estrutura e dos critérios na elaboração de um índice de sustentabilidade. Sustentabilidade em Debate, v. 8, n. 2, p. 30-43, ago. 2017. Disponível em:

http://periodicos.unb.br/index.php/sust/article/view/21516/19026. Acesso em: 22 jul. 2017. GUEDES, Dayane Raquel da Cruz. Análise dos serviços ecossistêmicos de provisão em dois sistemas estuarinos no litoral do Rio Grande do Norte, Brasil. 2018.

Dissertação (Mestrado em Geografia) - Universidade Federal do Rio Grande do Norte, Natal, RN, 2018.

IBAMA. Roteiro metodológico para a gestão de área de proteção ambiental. Brasília: Edição IBAMA, 2001.

IBGE. 2018. Disponível em: https://cidades.ibge.gov.br/brasil/rn/extremoz/panorama. Acesso em: 09 jul. 2018.

ICMBIO. Gestão de Pessoas: servidores especialistas em meio ambiente em exercício no ICMBIO. 2018. Disponível em:

http://qv.icmbio.gov.br/QvAJAXZfc/opendoc2.htm?document=painel corporativo 6476.qvw\& host=Local\&anonymous=true. Acesso em: $12 \mathrm{dez} .2018$.

INDICATORS of Sustainable Development: guidelines and methodologies. 3. ed. New York: United Nations Publication, 2007.

LIÇÕES aprendidas sobre o Diagnóstico para Elaboração de Planos de Manejo de Unidades de Conservação: comunidade de ensino e aprendizagem em planejamento de unidades de conservação. Brasília: WWF-Brasil, 2013. E-book. Disponível em:

https://d3nehc6yl9qzo4.cloudfront.net/downloads/diagnostico elaboracao planos manejo u cs.pdf. Acesso em: 26 jul. 2018.

LIMONT, M.; FISHER, D. Gestão participativa em unidades de conservação. In: DICK, E.; DANIELE, M. Alexandre; ZANINI, A. M. (orgs.). Gestão participativa em unidades de conservação: uma experiência na Mata Atlântica. Rio do Sul: APREMAVI, 2012.

MARTINS, Maria de Fátima; CÂNDIDO, Gesinaldo Ataíde. Índices de Desenvolvimento Sustentável para Localidades: uma proposta metodológica de construção e análise. Revista de Gestão Social e Ambiental - RGSA, São Paulo, v. 6, n. 1, p. 03- 19, jan./abr. 2012. Disponível em: https://rgsa.emnuvens.com.br/rgsa/article/view/229. Acesso em: 05 jul. 2018. MORSELLO, C. Áreas protegidas públicas e privadas: seleção e manejo. 2. ed. São Paulo: Annablume, 2006.

PRESCOTT-ALLEN, Robert. Barometer of Sustainability: measuring and communicating wellbeing and sustainable development, 1997. Disponível em: https://idl-bncidrc.dspacedirect.org/bitstream/handle/10625/54761/IDL-54761.pdf?sequence=1. Acesso em: 22 ago. 2018.

RIO GRANDE DO NORTE. Conselho Estadual de Meio Ambiente - CONEMA. Resolução CONEMA no 02/2007. Aprova o Regimento Interno do Conselho Gestor da Área de Proteção Ambiental Jenipabu, nos Municípios de Extremoz e Natal, no Estado do Rio Grande do Norte e dá outras providências. [2007]. Disponível em:

http://adcon.rn.gov.br/ACERVO/idema/DOC/DOC000000000033845.PDF. Acesso em: 26 jul. 2015.

RIO GRANDE DO NORTE. Decreto no 12620, de 17 de maio de 1995. Cria a Área de Proteção Ambiental (APA) Genipabu, nos Municípios de Extremoz e Natal e dá outras providências. [1995]. Disponível em: http://www.rn.gov.br/secretarias/idema/legislacao.asp. Acesso em: 26 jul. 2015.

RIO GRANDE DO NORTE. Decreto no 19.139, de 5 de junho de 2006. Cria o Conselho 
Gestor da Área de Proteção Ambiental (APA) Jenipabu, nos municípios de Extremoz e Natal e dá outras providências. [2006]. Disponível em:

http://adcon.rn.gov.br/ACERVO/idema/DOC/DOC000000000033844.PDF. Acesso em: 26 jul. 2015.

RIO GRANDE DO NORTE. Plano de Manejo da Área de Proteção Ambiental - APA Jenipabu: Relatório de Consolidação. Natal, 2009.

RODRIGUEZ, José Manuel. M.; SILVA, Edson V. da. Planejamento e Gestão Ambiental: subsídios da geocologia das paisagens e da teoria geossistêmica. Fortaleza: Edições UFC, 2013.

SALES, Vanda de Claudino. Geografia, sistemas e análise ambiental: abordagem crítica. GEOUSP: Espaço e Tempo, São Paulo, n. 16, p. 125-141, 2004. Disponível em: http://www.geografia.fflch.usp.br/publicacoes/Geousp/Geousp16/Artigo8.pdf. Acesso em 12 jul. 2016.

SALVIO, Geraldo Magela Morais. Áreas naturais protegidas e indicadores socioeconômicos: o desafio da conservação da natureza. Jundiaí: Paco Editorial, 2017. SILVA, Carlos Eduardo Menezes da et al. Conservation Unit System: Costs and Expenditures to Maintain the Natural Capital. An Evaluation of the State of Pernambuco's Reality. Revista Brasileira de Geografia Física, v. 11, n. 2, p. 661-673, 2018. Disponível em: https://periodicos.ufpe.br/revistas/rbgfe/article/view/234152/pdf. Acesso em: 01 dez. 2018.

SINGH, R. K. et al. An overview of sustainability assessment methodologies. Ecological Indicators, v. 15, n. 1, p. 281-299, 2012. Disponível em:

https://www.sciencedirect.com/science/article/pii/S1470160X11000240. Acesso em: 22 ago. 2018.

SOARES, Ilton Araújo; OLIVEIRA, Jorge Eduardo Lins, LIMA, Eduardo Rodrigues Viana. Conflitos socioambientais na Área de Proteção Ambiental de Jenipabu - RN. Revista Brasileira de Geografia Física, v.11, n. 2, p. 490-509, 2018. Disponível em: https://periodicos.ufpe.br/revistas/rbgfe/article/view/235886/pdf. Acesso em: 22 set. 2018. TAYRA, Flávio; RIBEIRO, Helena. Modelos de indicadores de sustentabilidade: síntese e avaliação crítica das principais experiências. Saúde e Sociedade, v. 15, n. 1, p. 84-95, 2006. Disponível em: http://www.scielo.br/scielo.php?script=sci arttext\&pid=S010412902006000100009 . Acesso em: 26 jul. 2015.

\title{
NOTAS DE AUTOR
}

\section{CONTRIBUIÇÃO DE AUTORIA}

\begin{abstract}
Ilton Araújo Soares - Concepção e elaboração do manuscrito; coleta e análise de dados; revisão e aprovação da versão final do trabalho.

William Gledson e Silva - Elaboração do manuscrito; participação na discussão dos resultados; revisão da versão final do trabalho.

Jorge Eduardo Lins Oliveira - Participação na discussão dos resultados; revisão da versão final do trabalho.
\end{abstract}

\section{FINANCIAMENTO}

Coordenação de Aperfeiçoamento de Pessoal de Nível Superior (CAPES)

CONSENTIMENTO DE USO DE IMAGEM

Não se aplica.

APROVAÇÃO DE COMITÊ DE ÉTICA EM PESQUISA

Não se aplica.

CONFLITO DE INTERESSES

Não se aplica. 


\section{LICENÇA DE USO}

Este artigo está licenciado sob a Licença Creative Commons CC-BY. Com essa licença você pode compartilhar, adaptar, criar para qualquer fim, desde que atribua a autoria da obra.

\section{HISTÓRICO}

Recebido em: 18-04-2019

Aprovado em: 22-08-2019 